\title{
A randomised, controlled trial of bosentan in severe COPD
}

\author{
D. Stolz*\#, H. Rasch ${ }^{\Uparrow}$, A. Linka+, M. Di Valentino ${ }^{\S}$, A. Meyer*, \\ M. Brutsche* and M. Tamm*
}

ABSTRACT: Pulmonary hypertension during exercise is common in severe chronic obstructive pulmonary disease (COPD). It was hypothesised that the use of the endothelin-receptor antagonist bosentan can improve cardiopulmonary haemodynamics during exercise, thus increasing exercise tolerance in patients with severe COPD.

In the present double-blind, placebo-controlled study, 30 patients with severe or very severe COPD were randomly assigned in a 2:1 ratio to receive either bosentan or placebo for 12 weeks. The primary end-point was change in the 6-min walking distance. Secondary end-points included changes in health-related quality of life, lung function, cardiac haemodynamics, maximal oxygen uptake and pulmonary perfusion patterns.

Compared with placebo, patients treated with bosentan during 12 weeks showed no significant improvement in exercise capacity as measured by the 6-min walking distance (mean \pm SD $331 \pm 123$ versus $329 \pm 94 \mathrm{~m}$ ). There was no change in lung function, pulmonary arterial pressure, maximal oxygen uptake or regional pulmonary perfusion pattern. In contrast, arterial oxygen pressure dropped, the alveolar-arterial gradient increased and quality of life deteriorated significantly in patients assigned bosentan.

The oral administration of the endothelin receptor antagonist bosentan not only failed to improve exercise capacity but also deteriorated hypoxaemia and functional status in severe chronic obstructive pulmonary disease patients without severe pulmonary hypertension at rest.

KEYWORDS: Endothelin-receptor antagonist, exercise capacity, pulmonary hypertension, treatment

ulmonary hypertension $(\mathrm{PH})$ at rest and during exercise is a very frequent complication in the natural history of chronic obstructive pulmonary disease (COPD) [1, 2]. Correspondingly, this condition has been reported in $20-91 \%$ of patients with severe COPD and/or emphysema [3, 4]. The presence of $\mathrm{PH}$ is commonly associated with more frequent use of healthcare resources and worse clinical outcome [5]. Remarkably, pulmonary artery pressure has been suggested to be the single best predictor of mortality in COPD [6].

In COPD, PH is generally of moderate severity, but the range of mean pulmonary artery pressures varies substantially [7]. Moderate and severe $\mathrm{PH}$ are present in 9.8 and $3.7 \%$, respectively, of the patients undergoing right heart catheterisation before lung volume reduction surgery [7]. Despite many uncertainties, studies indicate that $35 \%$ of all patients with severe COPD have pulmonary artery pressures of $>20 \mathrm{mmHg}$ at rest [8]. In addition, pulmonary pressures during

For editorial comments see page 541. exercise are greater than predicted by the pulmonary vascular resistance (PVR) equation in COPD, suggesting active pulmonary vasoconstriction on exertion [9]. Hence, of those patients without $\mathrm{PH}$ at rest, a further $52 \%$ are estimated to develop $\mathrm{PH}$ during exercise [5].

There are many pathological similarities between idiopathic pulmonary arterial hypertension $(\mathrm{PAH})$ and $\mathrm{PH}$ related to COPD. Like idiopathic $\mathrm{PAH}$, pulmonary arteries in patients with COPD show evidence of fibromuscular intimal thickening with a diffuse increase in smooth muscle cells within the intima [10]. In addition, the expression of endothelin-1 in pulmonary arteries is increased in all forms of PAH [11]. Endothelin-1 is a potent vasoconstrictor released by endothelial cells, which also exerts a mitogenic effect on arterial smooth muscle cells. Elevated endothelin-1 plasma levels are described in patients with severe COPD [12] and endothelial dysfunction has been demonstrated at both ends of the COPD spectrum [13].

The oral endothelin-1 receptor antagonist bosentan has been established as a safe and effective treatment in patients with idiopathic, scleroderma
AFFILIATIONS

${ }^{*}$ Clinic of Pneumology and

Pulmonary Cell Research,

"Divisions of Nuclear Medicine and

${ }^{\S}$ Cardiology, University Hospital

Basel, Basel, and

${ }^{+}$Division of Cardiology State

Hospital, Winterthur, Switzerland.

"Harvard School of Public Health,

Boston, MA, USA.

CORRESPONDENCE

D. Stolz

Clinic of Pulmonary Medicine and

Respiratory Cell Research

University Hospital Basel

Petersgraben 4

CH-4031 Basel

Switzerland

Fax: 41612654587

E-mail: dstolz@uhbs.ch

Received:

January 232008

Accepted after revision:

April 142008

\section{SUPPORT STATEMENT}

D. Stolz was partially supported by grants from Lichtenstein Foundation and Freiwillige Akademische

Gesellschaft (Basel, Switzerland).

\section{CLINICAL TRIAL}

This study is registered in the Current Controlled Trials Database (identifier number: ISRCTN98252311).

STATEMENT OF INTEREST A statement of interest for the study itself can be found at www.erj.ersjournals.com/misc/ statements.shtml 


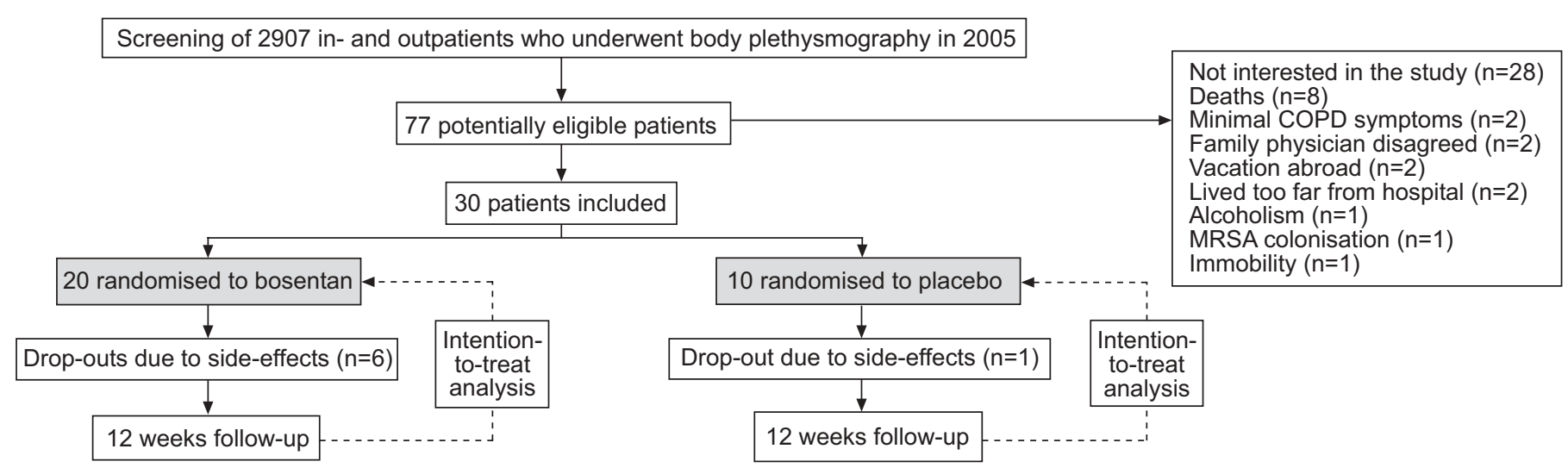

FIGURE 1. Flow diagram showing the trial design. COPD: chronic obstructive pulmonary disease; MRSA: methicillin-resistant Staphylococcus aureus.

and HIV-related PAH, chronic thromboembolic PH, Eisenmenger syndrome and porto-PH [14-18]. Therefore, it appears rational to consider whether the use of this class of drug might decrease pulmonary pressures and improve both right ventricular function and oxygen delivery during exercise, thereby increasing exercise tolerance in severe COPD. To test this hypothesis, a randomised, double-blind, placebo-controlled study was carried out to compare bosentan with placebo over a 12-week period in patients with severe or very severe COPD without severe $\mathrm{PH}$ at rest.

\section{MATERIALS AND METHODS}

The study was a prospective, randomised, single-centre, double-blind trial comparing bosentan with placebo in regard to exercise tolerance in patients with severe or very severe COPD. The trial was conducted from March 2006 through to March 2007 at the University Hospital Basel (Basel, Switzerland). The study protocol was reviewed and approved by the local ethics committee (Ethikkommission Beider, Basel) and registered in the Current Controlled Trials Database (ISRCTN98252311). Written informed consent was obtained from all participants before inclusion in the study.

\section{Patients}

Ambulatory patients were recruited who had symptomatic, severe or very severe COPD and/or emphysema (in classes IIIIV according to the Global Initiative for Chronic Obstructive Lung Disease classification), despite optimised therapy with short- and long-acting $\beta_{2}$-agonists, long-acting anticholinergics and inhaled steroids. Patients were excluded if they had: significant exacerbation of COPD within the last month; decompensate right or left heart failure; significant comorbidity resulting in reduced life expectancy; a severe mental disorder preventing appropriate judgement concerning study participation; insufficient technical quality in the echocardiographic evaluation; or known intolerance or formal contraindication for the use of bosentan.

In total, 30 patients were randomly assigned $62.5 \mathrm{mg}$ bosentan twice daily for the first 2 weeks followed by the target dose of $125 \mathrm{mg}$ twice daily, unless drug-related adverse events arose (e.g. increase in liver enzymes), or matching doses of placebo. Randomisation was computer-generated using the Almedica Drug Labelling System (Dorset, UK), with a block size of six and a 2:1 randomisation ratio (bosentan:placebo).

\section{Outcome measurements}

Patients were assessed on an outpatient basis after $24 \mathrm{~h}$ and at 2, 4, 8 and 12 weeks of treatment. The primary end-point was exercise capacity at week 12 and was measured by the 6-min walking test (6MWT) [19]. Secondary measures of efficacy included: maximal oxygen uptake $\left(V^{\prime} \mathrm{O}_{2}\right.$, max $)$ on cardiopulmonary exercise testing; cardiopulmonary performance as measured by Doppler echocardiography; lung function parameters as measured by body plethysmography; and perfusion pattern on thorax single photon emission computed tomography $(\mathrm{CT})$ and quantitative perfusion scintigraphy (SPECT; at baseline and week 12). Secondary measures of efficacy also included the Borg dyspnoea index, which was obtained immediately after completion of the 6MWT, and health-related quality of life, as assessed by the Short-Form-36 Health Survey (SF-36). Safety was appraised by the number of adverse events and laboratory assessment.

\section{Procedures}

6MWT and cardiopulmonary exercise testing

The 6MWT was performed according to the American Thoracic Society guidelines [19]. Cardiopulmonary exercise testing was performed using a telemetric mobile device (Oxycon Mobile ${ }_{\circledR}$ software v. 4.6; VIASYS Healthcare GmbH, Würzburg, Germany). Respiratory quotient, cardiac frequency, oxygen pulse, minute ventilation, $V^{\prime} \mathrm{O}_{2}$ and peripheral oxygen saturation were monitored and registered at real time during exercise.

\section{Echocardiography}

Cardiac morphological and functional parameters were assessed by comprehensive two-dimensional and Doppler echocardiography using a single investigator (GE Vivid FiVe; GEMS, Milwaukee, WI, USA) [20]. Echocardiography data were digitally stored and independently analysed by two investigators blinded to the patients' clinical data. PVR in Wood units and tissue doppler imaging of the mitral and tricuspid annulus were assessed as described previously [21].

\section{Lung function testing}

Pulmonary function was evaluated by body plethysmography and the carbon monoxide diffusion capacity (Jaeger, Wuerzburg, Germany). All testing was performed according to the European Respiratory Society standards [22]. 


\section{SPECT 99m-Tc-Nanocoll}

Perfusion scintigraphy was performed using $100 \mathrm{MBq}^{99 \mathrm{~m}} \mathrm{Tc}-$ MAA (TechneScan LyoMAA; Mallinckrodt Medical, Hazelwood, MO, USA) by intravenous injection. Each examination consisted of a planar data set followed by a three-dimensional (3D) SPECT combined with a low dose CT scan. A Siemens Dual Head SPECT-CT camera (SYMBIA $\mathrm{T}_{2}$; Siemens, Malvern, PA, USA) was used for all nuclear imaging. The SPECT and fused images were independently reviewed by two nuclear medicine investigators blinded to the patients' clinical data using a 3D workstation. The regional perfusion difference between baseline and 12 weeks, expressed in percentage, was calculated by subtracting the starting data set and the data obtained after the treatment. Images were qualitatively analysed, slice by slice for the extent and severity of morphological and perfusion abnormalities.

\section{Statistical analysis}

Power and sample size was calculated using the 6MWT before and after treatment as the primary outcome variable. Assumptions were based on the results of the only previous study performed in a similar population (an open-label trial) [23]. Considering a mean \pm SD improvement in the 6MWT from $351 \pm 49$ to $433 \pm 52 \mathrm{~m}$ after treatment, eight patients were required in each study arm to achieve a significance level of $p<0.05$ with a power of 0.85 performing a two-sided unpaired t-test. Taking into account the small size and open label character of the published study, the present authors decided to double the size of the active treatment arm. Considering a $25 \%$ dropout rate after assignment to the study medication, 30 inclusions were planned. The sample size of 30 patients provided the study with a calculated power of 0.93 to detect a 50 -m change in the $6 \mathrm{MWT}$ at a significance level of $\mathrm{p}<0.05$ performing a two-sided unpaired t-test.

The results are presented as the mean \pm SD for all variables that were normally distributed, and as the median (interquartile range) for variables that were not normally distributed. The significance of the differences from baseline to week 12 between the treatment groups were calculated for all parameters using a linear, mixed effect model. The proportion of patients who withdrew because of side-effects was analysed using Fisher's exact test. The primary end-point statistical analysis was carried out on an intention-to-treat basis. All p-values were two-tailed.

\section{RESULTS}

In total, 30 patients were included in the study; 20 were assigned bosentan and 10 were assigned placebo (fig. 1). All patients remained in the study until the last patient had completed the assessments at week 12, unless the patients dropped out due to side-effects. Of those randomised, one $(10 \%)$ patient in the placebo group and six (30\%) in the bosentan group discontinued the study agent due to adverse events $(p=0.372)$. An acute exacerbation of COPD requiring intensive care admission led to study withdrawal in the placebo group. Reasons for treatment discontinuation in the bosentan group were: drowsiness $(n=2)$; dyspnoea $(n=2)$; drowsiness and lower extremity oedema refractory to medical therapy $(n=1)$; and subjective cervical swelling combined with constipation $(n=1)$. One patient in the placebo group developed dyspnoea after the presumptive increase in medication dosage at 2 weeks, thus requiring a

\begin{tabular}{|c|c|c|c|c|}
\hline \multirow[t]{2}{*}{ TABLE 1} & \multicolumn{4}{|c|}{$\begin{array}{l}\text { Demographic and haemodynamic } \\
\text { characteristics at baseline }\end{array}$} \\
\hline & & Placebo & Bosentan & p-value \\
\hline Subjects n & & 10 & 20 & \\
\hline \multicolumn{5}{|c|}{ Demographic variables } \\
\hline Age yrs & & $65 \pm 7.9$ & $69.5 \pm 8.8$ & 0.184 \\
\hline Male & & $7(70)$ & $11(55)$ & 0.694 \\
\hline Weight kg & & $76.9 \pm 16.4$ & $66.3 \pm 14.0$ & 0.075 \\
\hline Height $\mathrm{cm}$ & & $165 \pm 6.1$ & $166.9 \pm 6.9$ & 0.464 \\
\hline Body mass & index & $28.1 \pm 4.7$ & $24.0 \pm 5.9$ & 0.064 \\
\hline Pack-yrs & & $80 \pm 38$ & $38 \pm 21$ & 0.001 \\
\hline Ex-smoker & & $8(80)$ & $18(90)$ & 0.584 \\
\hline Current sm & ker & $2(20)$ & $2(10)$ & 0.584 \\
\hline \multicolumn{5}{|c|}{ Symptoms } \\
\hline Dizziness & & $4(40)$ & $4(20)$ & 0.384 \\
\hline Peripheral & edema & $2(20)$ & $5(25)$ & 1 \\
\hline \multicolumn{5}{|c|}{ Physical examination } \\
\hline Wheezing & & $2(20)$ & $8(40)$ & 0.420 \\
\hline Rales & & $1(10)$ & $1(5)$ & 1 \\
\hline \multicolumn{5}{|c|}{ GOLD stages } \\
\hline$\| I^{\#}$ & & $6(60)$ & $11(55)$ & 1 \\
\hline $\mathrm{IV}^{*}$ & & $4(40)$ & $9(45)$ & \\
\hline \multicolumn{5}{|c|}{ Exercise tolerance } \\
\hline 6-min walki & g distance $\mathrm{m}$ & $331 \pm 116$ & $339 \pm 81$ & 0.817 \\
\hline Borg dyspr & oea index levels & $5.3 \pm 2.4$ & $5.1 \pm 2.1$ & 0.084 \\
\hline \multicolumn{5}{|c|}{ Regular medication use } \\
\hline Long-term & xygen therapy & $3(30)$ & $8(40)$ & 0.702 \\
\hline Chronic dic & etic use & $3(30)$ & $5(25)$ & 1 \\
\hline Short-actin & $\beta_{2}$-agonists & $10(100)$ & $20(100)$ & 1 \\
\hline Long-acting & $\beta_{2}$-agonists & $10(100)$ & $20(100)$ & 1 \\
\hline Long-acting & -anticholinergics & $10(100)$ & $20(100)$ & 1 \\
\hline Inhaled ste & oids & $10(100)$ & $20(100)$ & 1 \\
\hline \multicolumn{5}{|c|}{ Vital signs } \\
\hline Respiratory & frequency breaths $\cdot \min ^{-1}$ & $18 \pm 3$ & $20 \pm 5$ & 0.291 \\
\hline Peripheral & ${ }_{2}$ saturation $\%$ & $92(4)$ & $93(4)$ & 0.510 \\
\hline$f \mathrm{c}$ beats $\cdot \mathrm{mi}$ & & $90 \pm 12$ & $88 \pm 15$ & 0.759 \\
\hline Systolic blo & d pressure $\mathrm{mmHg}$ & $142 \pm 19$ & $129 \pm 16$ & 0.069 \\
\hline Diastolic bl & od pressure $\mathrm{mmHg}$ & $87 \pm 7$ & $78 \pm 9$ & 0.009 \\
\hline \multicolumn{5}{|c|}{ Echocardiography } \\
\hline $\begin{array}{c}\text { Pulmonary } \\
\quad \text { at rest } \geqslant\end{array}$ & $\begin{array}{l}\text { nypertension } \\
30 \mathrm{mmHg}^{+}\end{array}$ & $6(60)$ & $14(70)$ & 0.584 \\
\hline $\begin{array}{l}\text { Median est } \\
\text { Ppa at re }\end{array}$ & $\begin{array}{l}\text { nated systolic } \\
\mathrm{t} \mathrm{mmHg}^{+}\end{array}$ & $37(20-42)$ & 32 (29-38) & 0.779 \\
\hline Left ventric & lar ejection fraction \% & $57 \pm 9$ & $61 \pm 10$ & 0.321 \\
\hline \multicolumn{5}{|c|}{$\begin{array}{l}\text { Data are presented as mean } \pm \mathrm{SD}, \mathrm{n}(\%) \text { or median (interquartile range), unless } \\
\text { otherwises stated. GOLD: Global Initiative for Chronic Obstructive Lung } \\
\text { Disease; fC: cardiac frequency; Ppa: pulmonary arterial pressue. }{ }^{*}: 30 \% \\
\text { predicted less than forced expiratory volume in one second } \leqslant 50 \% \text { pred; } \\
\text { ?: forced expiratory volume in one second } \leqslant 30 \% \text { pred; }{ }^{+} \text {: estimated pulmonary } \\
\text { pressures without adding central venous pressure. }\end{array}$} \\
\hline
\end{tabular}

lower maintenance dosage up to 12 weeks. Lower extremity oedema warranting diuretic therapy was observed in four patients receiving bosentan and in one patient receiving placebo. In two cases, the bosentan dosage had to be halved after 8 weeks due to reversible elevation of liver enzymes. 

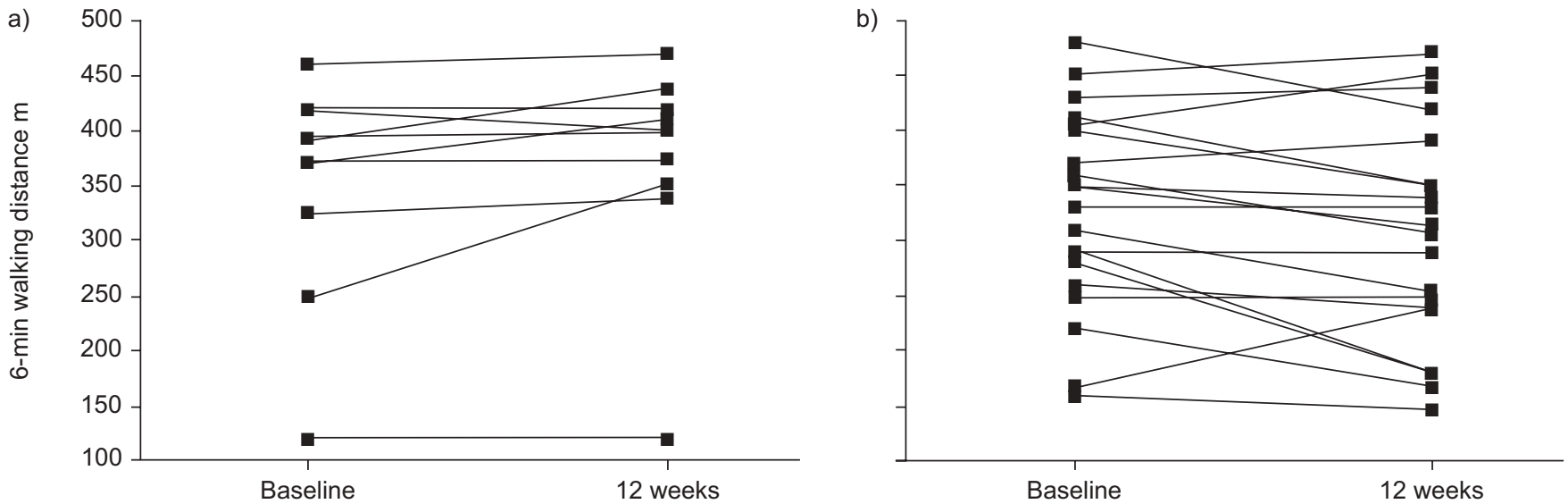

FIGURE 2. Individual patient data showing the 6-min walking distance at baseline and at 12 weeks in patients assigned a) placebo $(n=10)$ and b) bosentan $(n=20)$. The changes in the 6-min walking distance were similar across both treatment groups $(p=0.474)$. The mean \pm SD distance walked in 6 min decreased by $10 \mathrm{~m}$ in patients assigned bosentan (from $339 \pm 81 \mathrm{~m}$ at baseline to $329 \pm 94 \mathrm{~m}$ at week 12, $\mathrm{p}=0.040$ ), and remained unchanged in those given placebo (331 $\pm 116 \mathrm{~m}$ at baseline and $331 \pm 123 \mathrm{~m}$ at week $12, \mathrm{p}=0.100)$.

Overall, treatment groups were well matched with respect to baseline characteristics (table 1). All patients were in the World Health Organization functional class III or IV at baseline. Use of concomitant medication (including long-term oxygen therapy and diuretics) did not differ between groups. The only significant differences between groups were the higher cigarette consumption in patients assigned placebo $(p=0.001)$ and the lower diastolic blood pressure in patients assigned bosentan $(p=0.009)$. Left ventricular ejection fraction was preserved $(\geqslant 45 \%)$ in all cases.

\section{Primary end-point: 6MWT}

Changes from baseline to week 12 in the 6MWT were similar across treatment groups $(p=0.474$; fig. 2$)$. The mean $\pm S D$ distance walked in 6 min decreased by $10 \mathrm{~m}$ in patients assigned bosentan (from $339 \pm 81$ at baseline to $329 \pm 94 \mathrm{~m}$ at week 12; $\mathrm{p}=0.040$ ), and remained unchanged in those assigned placebo $(331 \pm 116$ at baseline and $331 \pm 123 \mathrm{~m}$ at week $12 ; \mathrm{p}=0.100)$.

\section{Secondary end-points}

In the treatment groups, no significant differences were observed in the change from baseline to week 12 in lung function or cardiopulmonary exercise testing parameters (table 2). Cardiopulmonary performance as assessed by echocardiography displayed a significant increase in PVR only in patients randomised to placebo ( $p=0.006$; table 3$)$. There was no change in the Borg dyspnoea index $(\mathrm{p}=0.932)$. Conversely, arterial partial pressure of oxygen $\left(\mathrm{PO}_{2}\right)$ decreased significantly in patients assigned bosentan compared with those assigned placebo $(p=0.029)$. In the bosentan group, mean $\pm \mathrm{SD}$ arterial $\mathrm{PO}_{2}$ was $65.2 \pm 10.5,58.8 \pm 8.6$ and $60.7 \pm 7.5 \mathrm{mmHg}$ at baseline, 4 weeks and 12 weeks, respectively. The corresponding values for the placebo group were $66.1 \pm 15.1,64.4 \pm 6.9$ and $65.7 \pm 10.9 \mathrm{mmHg}$, respectively. The decrease in arterial oxygen pressure was associated with a significant increase in alveolar-arterial gradient in the group treated with bosentan compared with patients receiving placebo (fig. 3). Health-related quality of life, particularly the global physical health domain in the SF-36, deteriorated in patients' assigned bosentan compared with those assigned placebo (table 4). Haematological and hepatic laboratorial assessments did not reveal any relevant toxicity of bosentan (data not shown). Circulating brain-natriuretic peptide remained similar in both treatment groups $(p=0.979)$. The regional perfusion pattern on the thoracic SPECT-CT did not change after 12 weeks therapy with bosentan (figs 4 and 5). Compared with baseline, mean \pm SD change in perfusion of the right lung at 12 weeks was $0.88 \pm 2.7$ and $0.07 \pm 1.7 \%$ for the placebo and bosentan group, respectively $(p=0.381)$. The respective values for the left lung were $-0.66 \pm 2.7$ and $-0.142 \pm 1.7 \%(p=0.576)$.

\section{DISCUSSION}

The current results show that oral administration of a dual endothelin-receptor antagonist failed to improve exercise capacity in patients with severe COPD. Furthermore, bosentan did not positively affect any secondary end-point studied, including cardiopulmonary haemodynamics at rest as assessed by echocardiography. Finally, and most importantly, therapy with bosentan was associated with a significant decrease in arterial oxygen pressure and health-related quality of life. Hence, in patients with severe COPD without severe $\mathrm{PH}$ at rest, therapy with bosentan was not beneficial and resulted in relevant functional status deterioration.

The present study is the first to report the results of a randomised, placebo-controlled trial using an endothelinreceptor antagonist in patients with severe COPD [24]. Unselective vasodilators (i.e. calcium-channel blockers) have been previously evaluated in several clinical studies. The acute administration of nifedipine is suggested to reduce pulmonary pressures and increase cardiac output both at rest and during exercise $[9,25]$. However, nifedipine inhibits hypoxic pulmonary vasoconstriction [26], leading to worsening of the ventilation-perfusion relationship and to lower arterial $\mathrm{PO}_{2}[9,27]$. Moreover, clinical results of long-term treatment with calciumchannel blockers in COPD have been disappointing, showing that both pulmonary haemodynamics and clinical status either deteriorated or remained unchanged after treatment. The efficacy of newer pulmonary vasodilators in patients with COPD has only been described in one case series [23]. 
TABLE 2 Lung function testing and cardiopulmonary exercise test parameters

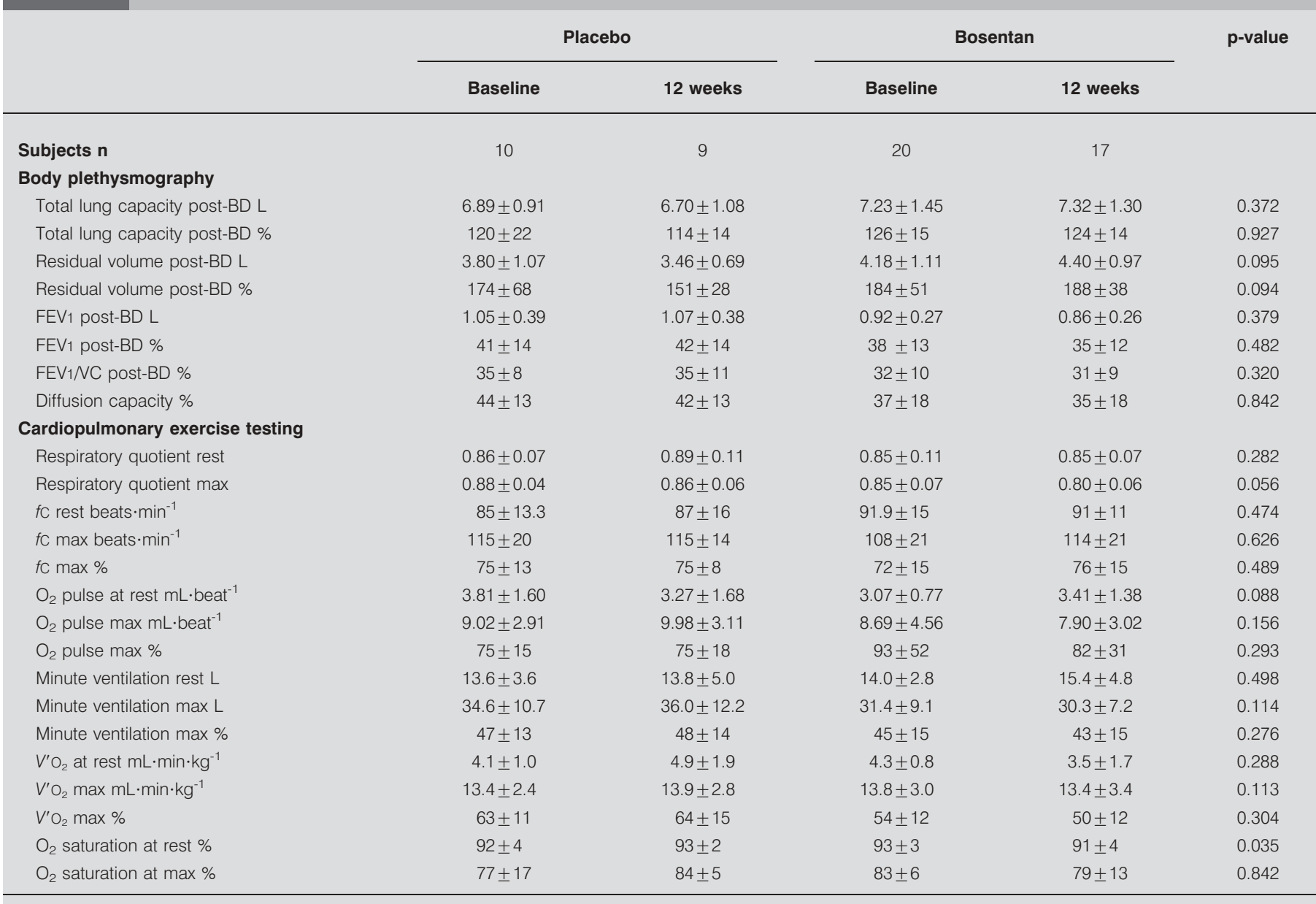

Data are presented as mean \pm SD, unless otherwise stated. BD: bronchodilator; FEV1: forced expiratory volume in one second; VC: vital capacity; fC: cardiac frequency; $V^{\prime} \mathrm{O}_{2}$ : maximal oxygen uptake.

In the present placebo-controlled trial, therapy with the pulmonary vasodilator bosentan proved ineffective in improving exercise tolerance in patients with severe COPD without severe $\mathrm{PH}$ at rest. Conversely, bosentan has been beneficial in improving exercise capacity, cardiac index, right ventricular systolic function, and left ventricular early diastolic filling in patients with idiopathic $\mathrm{PH}[14,28]$. However, in contrast to $\mathrm{PH}$ related to COPD, patients with idiopathic $\mathrm{PH}$ demonstrate preponderant right ventricular dysfunction leading to decreased cardiac index and major cardiovascular limitation in exercise testing. To date, it is unclear to what extent right ventricular dysfunction during exercise limits exercise tolerance in severe COPD [24]. In the present study, patients with COPD presented well-preserved right ventricular function at rest with tricuspidal annular motion values, in particular, above those known to worsen prognosis. Cardiopulmonary exercise testing profile was typical of a major ventilatory limitation (maximum respiratory quotient less than one and maximum ventilation approximately equal to maximal minute ventilation). Therefore, it remains questionable whether improvement in right ventricular function during exercise can enhance exercise tolerance at all in patients with severe COPD without manifesting right ventricular dysfunction in the resting state.

In contrast to previous reports on echocardiographic assessment in idiopathic $\mathrm{PH}$ and $\mathrm{PH}$ associated with connective tissue disease [28], the present authors failed to notice any relevant change in cardiopulmonary haemodynamics at rest in patients with COPD receiving bosentan. Echocardiography has been put forward as a useful tool in patients with suspected $\mathrm{PH}$ if right heart catheterisation is not feasible or warranted [29]. However, it might be imprecise in determining actual pressures compared with invasive evaluation in a portion of patients and its inherent limitations in COPD have been extensively described previously [30]. Furthermore, haemodynamics in the resting state improve only marginally in most patients even when their clinical response to therapy appears to be excellent [31]. Thus, resting haemodynamics might not necessarily reflect changes occurring with exercise [31].

Interestingly, a statistically significant increase of pulmonary vascular resistance, as assessed by echocardiography, was observed in patients randomised to the placebo group. 


\begin{tabular}{|c|c|c|c|c|c|}
\hline Subjects $\mathrm{n}$ & 10 & 9 & 20 & 14 & \\
\hline \multicolumn{6}{|l|}{ Cardiopulmonary haemodynamics } \\
\hline Tricuspid annular motion mm & $24.4 \pm 2.7$ & $22.5 \pm 2.4$ & $21.0 \pm 4.5$ & $22.7 \pm 3.6$ & 0.059 \\
\hline Early diastolic velocity $\mathrm{RV} \mathrm{cm} \cdot \mathrm{s}^{-1}$ & $0.44 \pm 0.09$ & $0.40 \pm 0.08$ & $0.44 \pm 0.11$ & $0.41 \pm 0.12$ & 0.512 \\
\hline Late diastolic velocity RV & $0.46 \pm 0.12$ & $0.46 \pm 0.09$ & $0.44 \pm 0.13$ & $0.39 \pm 0.07$ & 0.338 \\
\hline Early diastolic/late diastolic velocity RV & $1.00 \pm 0.30$ & $0.88 \pm 0.15$ & $0.99 \pm 0.23$ & $1.07 \pm 0.33$ & 0.142 \\
\hline \multicolumn{6}{|l|}{ Tissue doppler imaging } \\
\hline Cardiac index $L \cdot \min \cdot \mathrm{m}^{2}$ & $3.3 \pm 0.79$ & $3.39 \pm 0.58$ & $2.45 \pm 0.41$ & $2.66 \pm 0.65$ & 0.296 \\
\hline
\end{tabular}

Data are presented as median (interquartile range) or mean $\pm \mathrm{SD}$, unless otherwise stated. Ppa: pulmonary arterial pressure; RV: right ventricle ${ }^{\#}$ : estimated pulmonary pressures without adding central venous pressure.

Considering the slow progression of mean pulmonary arterial pressures, PVR would be expected to remain unchanged within 12 weeks in COPD patients during the stable state of the disease. Therefore, taking into account the limitations of echocardiography in this patient population, the present authors believe that this finding most likely represents an artefact. In any case, the clinical impact of an increase in PVR is suggested to be limited in the context of unchanged exercise capacity and $V^{\prime} \mathrm{O}_{2}$, max.

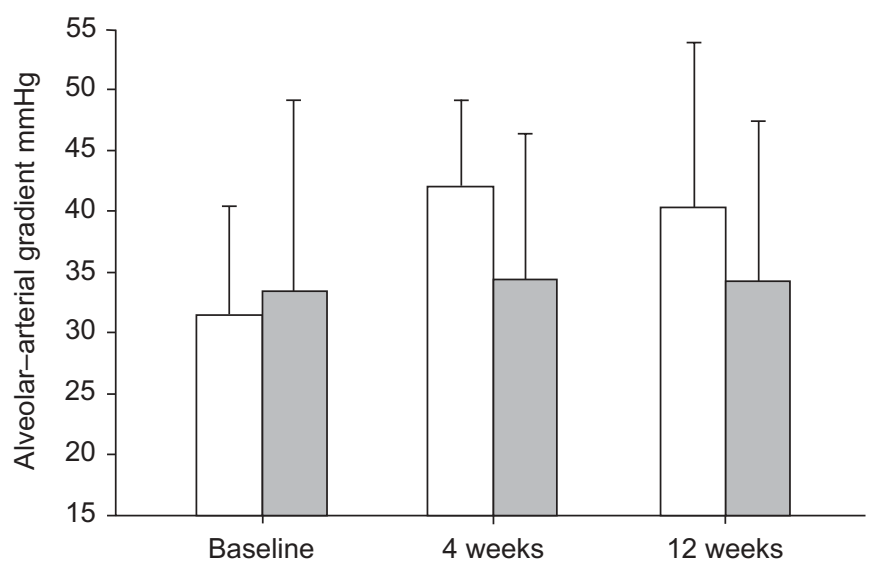

FIGURE 3. Alveolar-arterial gradient at baseline, 4 weeks and 12 weeks in patients assigned bosentan $(\square)$ and placebo $(\square)$. The alveolar-arterial gradient increased significantly in patients assigned bosentan compared with those assigned placebo $(p=0.029)$. In the bosentan group, median (interquartile range) alveolar-arterial gradient was 31.4 (28.1-37.1), 42.0 (37.4-44.5) and 40.4 (31.544.9) $\mathrm{mmHg}$ at baseline, 4 weeks and 12 weeks, respectively. The corresponding values for the placebo group were 33.4 (32.5-48.2), 34.4 (29.3-41.3), and 34.3 (20.9-42.8) mmHg, respectively.
Hypoxic pulmonary vasoconstriction has been suggested to be a factor leading to increased right ventricular diastolic pressures and impaired exercise capacity in COPD [24]. Accordingly, inhaled nitric oxide, a selective pulmonary vasodilator, has been reported to improve gas exchange during exercise and increase exercise tolerance in patients with COPD [32]. The pulmonary vasodilator bosentan could have potentially improved exercise tolerance by inhibiting exercised-induced hypoxic vasoconstriction in selected parts of the emphysematous lung. The present study has evaluated COPD patients using SPECT, which concomitantly appraises parenchyma morphology and changes in regional and global perfusion patterns. Compared with the placebo group, patients with COPD receiving bosentan developed hypoxaemia as assessed by blood gas analysis and pulse oxymetry. The decrease in arterial oxygen pressures was associated with a significant widening of alveolar-arterial gradient, thus suggesting that bosentan enhances ventilation-perfusion mismatching or intrapulmonary right-to-left microshunting [2]. No evidence of change was found in qualitative pulmonary perfusion patterns by SPECT in patients receiving bosentan, i.e. there was no redistribution of blood flow within pulmonary regions. Therefore, it is hypothesised that the decrease in arterial oxygen pressure could be attributed to a quantitative perfusion augmentation [2,9]. The marked initial decrease in arterial $\mathrm{PO}_{2}$ at 4 weeks, followed by a secondary increase at 12 weeks, suggests a consequential adjustment to the vasodilator effect in patients assigned bosentan. In patients treated with bosentan, fluid retention could have been another possible cause of decrease in oxygen arterial pressure and widening in alveolar-arterial gradient. Although body weight remained unchanged during the 3-month study period, patients receiving bosentan more often required prescription of a diuretic due to low extremity oedema. Hence, fluid retention might have caused or aggravated hypoxaemia in the 
TABLE 4 Health-related life quality as assessed by the Short-Form-36 Health Survey (SF-36) at baseline and after therapy

\begin{tabular}{|c|c|c|c|c|c|}
\hline & \multicolumn{2}{|c|}{ Placebo } & \multicolumn{2}{|c|}{ Bosentan } & \multirow[t]{2}{*}{ p-value } \\
\hline & Baseline & 12 weeks & Baseline & 12 weeks & \\
\hline Subjects $\mathrm{n}$ & 10 & 9 & 20 & 14 & \\
\hline Physical functioning & $43.3 \pm 28.1$ & $55.6 \pm 20.1$ & $27.5 \pm 15.3$ & $23.2 \pm 19.9$ & 0.067 \\
\hline Role limitations due to physical health & $23.0 \pm 38.1$ & $53.1 \pm 47.1$ & $16.3 \pm 33.7$ & $7.1 \pm 26.7$ & 0.082 \\
\hline Vitality & $47.8 \pm 20.0$ & $50.0 \pm 25.2$ & $36.4 \pm 19.3$ & $34.6 \pm 18.5$ & 0.571 \\
\hline Social functioning & $70.0 \pm 36.4$ & $89.1 \pm 15.6$ & $58.1 \pm 32.0$ & $57.1 \pm 28.5$ & 0.230 \\
\hline Role limitations due to emotional problems & $63.3 \pm 45.7$ & $79.2 \pm 35.4$ & $43.3 \pm 49.7$ & $59.5 \pm 49.2$ & 0.970 \\
\hline Mental health & $76.0 \pm 19.2$ & $87.1 \pm 13.5$ & $66.6 \pm 15.0$ & $64.9 \pm 17.0$ & 0.023 \\
\hline Total physical health & $47.4 \pm 23.2$ & $61.1 \pm 21.5$ & $38.5 \pm 14.8$ & $34.9 \pm 18.3$ & 0.032 \\
\hline Total mental health & $61.6 \pm 23.4$ & $68.9 \pm 21.4$ & $50.6 \pm 20.7$ & $51.1 \pm 20.8$ & 0.263 \\
\hline
\end{tabular}

Data are presented as mean $\pm \mathrm{SD}$, unless otherwise stated

group of patients treated with bosentan. Finally, the antagonism of endothelin-1 receptors might lead to a reduction of the peripheral carotid body sensitivity to arterial hypoxia, thus decreasing the ventilatory response to hypoxia [33]. However, a decrease in respiratory rate does not explain the increase in alveolar-arterial gradient observed in the present study and the respiratory rate remained unchanged during drug treatment in the patients. Moreover, more recent data suggest that circulating endothelin does not play an important role in peripheral chemoreceptor activation by acute hypoxia [34].

In contrast to patients receiving placebo, health-related quality of life deteriorated significantly in the bosentan group. It is noteworthy that the decline in quality of life was driven by the physical health domain of the SF-36. The enhanced perception of physical limitation and symptoms is suggested to reflect hypoxaemia associated with vasodilator therapy. The wellknown placebo effect in participants of a clinical trial was also evident in the present study, as noted by the improvement in mental and physical health domains in the placebo group. In addition, more patients in the bosentan group dropped out of the study due to side-effects of the medication. Although the dropout rate was not statistically significant in comparing both randomised groups, patients treated with bosentan reported increased dyspnoea, drowsiness and more often required diuretics due to peripheral oedema. These observations corroborate the unfavourable effect of this class of drugs in patients with COPD. Accordingly, a preliminary report
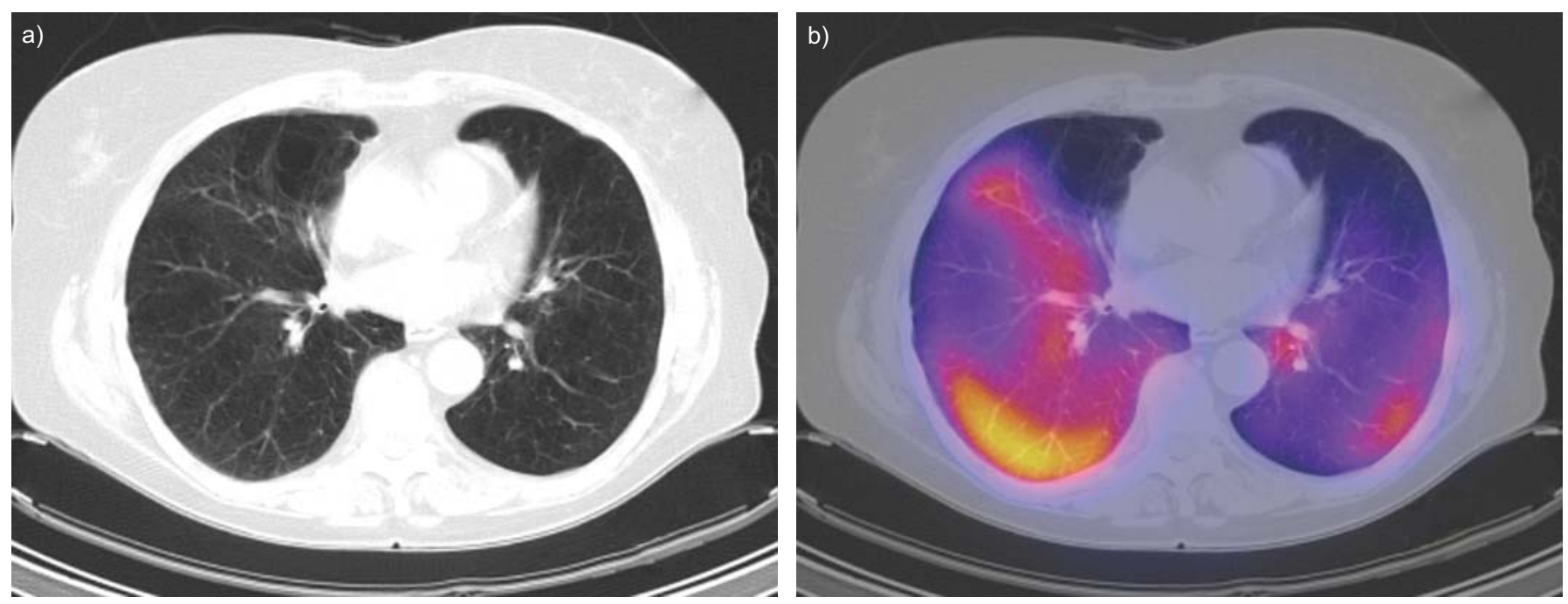

FIGURE 4. a) Transversal thoracic-computed tomography (CT) scan showing emphysematous changes in the right anterior upper lobe. b) Transversal fusion image combining a thoracic CT scan and perfusion signal. Colour-coded areas denote perfusion of lung parenchyma (yellow: high-perfusion areas; blue: low-perfusion areas; red: intermediate perfusion; black: no perfusion). 


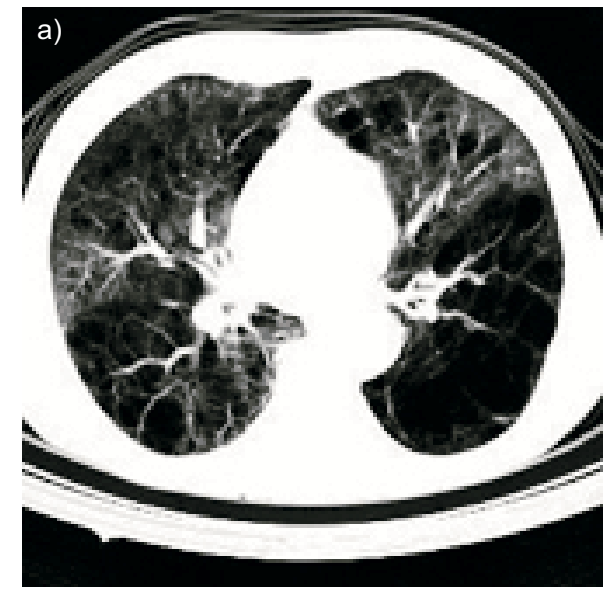

b)

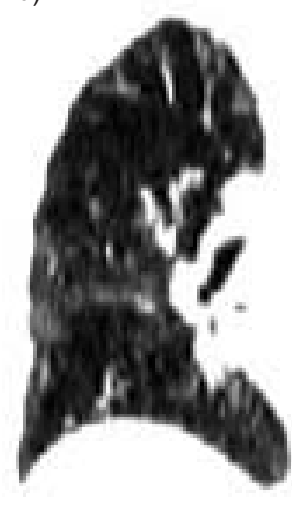

d)
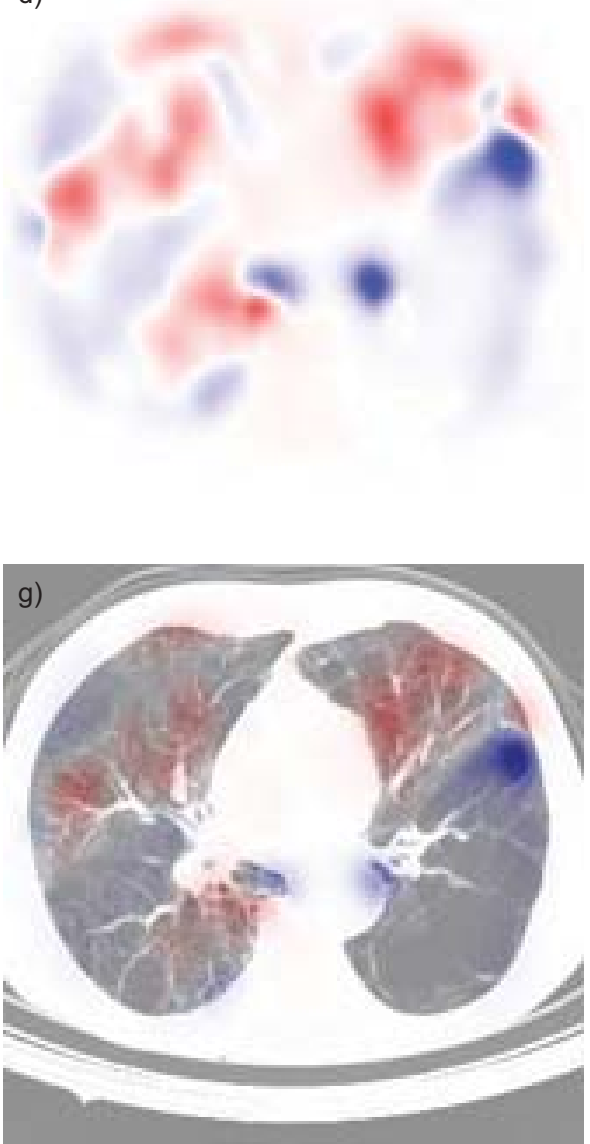

e)

h)

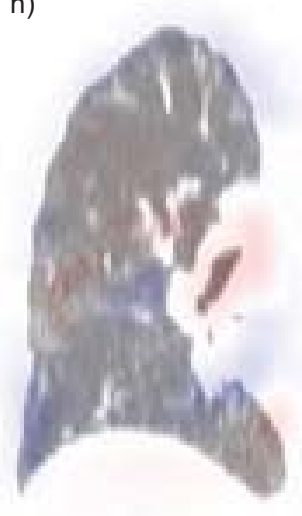

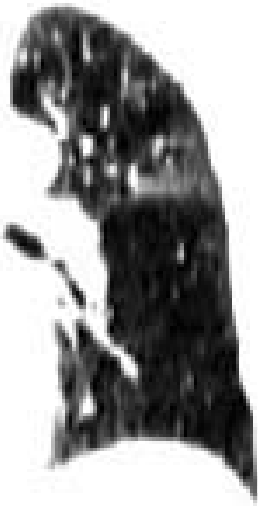

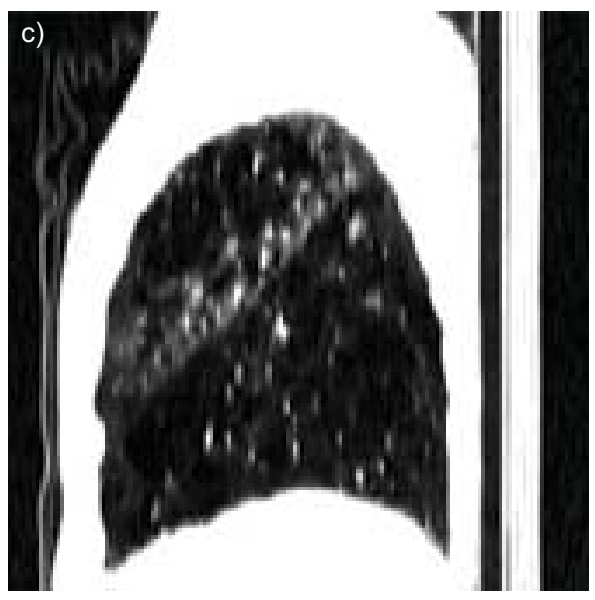

f)
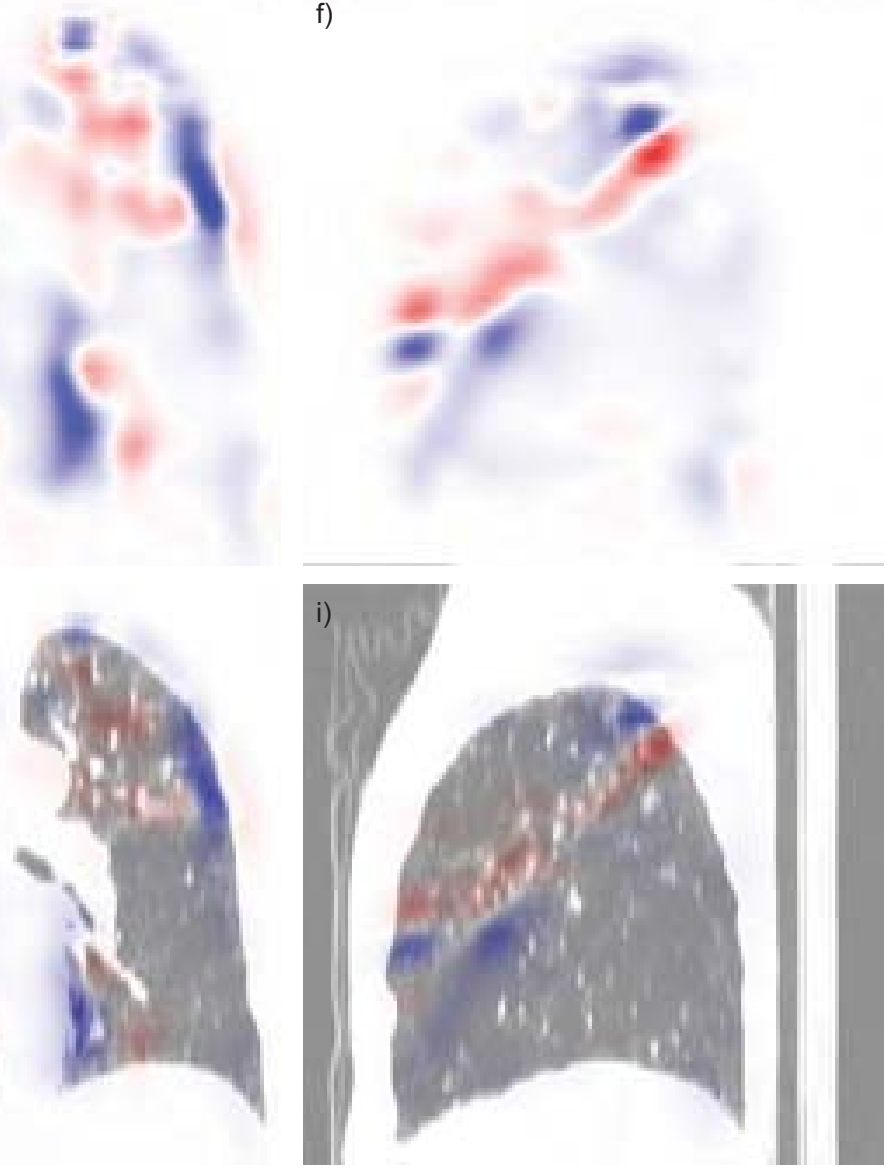

FIGURE 5. Transversal, coronal and sagital thoracic computed tomography (CT) scans showing a-c) the pulmonary morphology, $d-f$ ) the perfusion signal showing the perfusion difference between baseline and 12 weeks (blue: decreased perfusion at 12 weeks compared with baseline; red: increased perfusion at 12 weeks compared with baseline), and g-i) fusion thoracic CT and perfusion signal images combining morphology and perfusion.

suggests that sildenafil, another pulmonary vasodilator, which selectively inhibits cGMP-specific phosphodiesterase 5, is equally ineffective in improving exercise capacity in patients with COPD [35].

Several limitations of the present study need to be mentioned. First, a single-centre study was conducted, which included a relatively small number of patients. However, due to the well-defined findings of the study, it seems unlikely that contradicting results would be found by investigating a larger population. Moreover, the sample size of the study provided enough power to allow statistically significant inferences about the detrimental effect of bosentan in several domains, thus excluding, by definition, a type II or $\beta$-error. Additionally, a major weakness of the study was that no invasive assessment of pulmonary arterial pressures, i.e. cardiac catheterisation including exercise testing, was performed. By refraining from catheterisation, pulmonary pressures at rest could not be 
reliably measured and the extent of $\mathrm{PH}$ during exercise could not be proved. Considering the very weak correlation between echocardiographic estimates of pulmonary artery pressures and right heart catheterisation, as well as the poor test characteristics (e.g. sensitivity and specificity) of echocardiographic assessments in patients with severe COPD [30], the echocardiographic estimations of pressure, flow and resistance reported in the present study are rather illustrative and might not stand the test of invasive confirmation. Finally, the patients included in this trial did not have severe $\mathrm{PH}$ at rest. Therefore, the current results are only generalisable to the majority of patients with severe COPD, who usually only present with mild-to-moderate $\mathrm{PH}$ during exercise [7], and may not apply to the uncommon cases of disproportional $\mathrm{PH}$ associated with COPD. In this context, these findings do not rule out that bosentan (or other endothelin-receptor antagonists) may be efficacious in patients with less severe airflow obstruction, more severe $\mathrm{PH}$ or in the selected COPD patients with clearly documented cardiovascular limitation to exercise capacity.

In conclusion, the current findings suggest that therapy with the dual endothelin-receptor antagonist bosentan is not beneficial and results in relevant functional status deterioration in patients with chronic obstructive pulmonary disease without severe pulmonary hypertension at rest.

\section{ACKNOWLEDGEMENTS}

The authors would like to thank: A. Schötzau and U. Simmen (Schötzau and Simmen Statistical Consulting, Basel, Switzerland) for statistical advice, M. Leo, G. Lüdin, G. Novicic, J. Gebhard, D. Wissler (Lung function laboratory, Clinic of Pneumology and Pulmonary Cell Research, University Hospital Basel, Basel) for lung function assessments; and K. Bögl and K. Bruppacher (Medical Department, Actelion Pharma AG, Baden, Switzerland) for logistical support.

\section{REFERENCES}

1 Barbera JA, Peinado VI, Santos S. Pulmonary hypertension in chronic obstructive pulmonary disease. Eur Respir J 2003; 21: 892-905.

2 Naeije R, Barbera JA. Pulmonary hypertension associated with COPD. Crit care 2001; 5: 286-289.

3 Burrows B, Kettel LJ, Niden AH, Rabinowitz M, Diener CF. Patterns of cardiovascular dysfunction in chronic obstructive lung disease. New Engl J Med 1972; 286: 912-918.

4 Scharf SM, Iqbal M, Keller C, Criner G, Lee S, Fessler HE. Hemodynamic characterization of patients with severe emphysema. Am J Respir Crit Care Med 2002; 166: 314-322.

5 Kessler R, Faller M, Fourgaut G, Mennecier B, Weitzenblum E. Predictive factors of hospitalization for acute exacerbation in a series of 64 patients with chronic obstructive pulmonary disease. Am J Respir Crit Care Med 1999; 159: 158-164.

6 Weitzenblum E, Hirth C, Ducolone A, Mirhom R, Rasaholinjanahary J, Ehrhart M. Prognostic value of pulmonary artery pressure in chronic obstructive pulmonary disease. Thorax 1981; 36: 752-758.

7 Thabut G, Dauriat G, Stern JB, et al. Pulmonary hemodynamics in advanced COPD candidates for lung volume reduction surgery or lung transplantation. Chest 2005; 127 1531-1536.

8 Weitzenblum E, Sautegeau A, Ehrhart M, Mammosser M, Hirth C, Roegel E. Long-term course of pulmonary arterial pressure in chronic obstructive pulmonary disease. Am Rev Respir Dis 1984; 130: 993-998.

9 Agusti AG, Barbera JA, Roca J, Wagner PD, Guitart R, Rodriguez-Roisin R. Hypoxic pulmonary vasoconstriction and gas exchange during exercise in chronic obstructive pulmonary disease. Chest 1990; 97: 268-275.

10 Santos S, Peinado VI, Ramirez J, et al. Characterization of pulmonary vascular remodelling in smokers and patients with mild COPD. Eur Respir J 2002; 19: 632-638.

11 Giaid A, Yanagisawa M, Langleben D, et al. Expression of endothelin-1 in the lungs of patients with pulmonary hypertension. New Engl J Med 1993; 328: 1732-1739.

12 Stolz D, Christ-Crain M, Morgenthaler NG, et al. Plasma pro-adrenomedullin but not plasma pro-endothelin predicts survival in exacerbations of COPD. Chest 2008; Epub ahead of print [PMID: 18490402].

13 Dinh-Xuan AT, Higenbottam TW, Clelland CA, et al. Impairment of endothelium-dependent pulmonary-artery relaxation in chronic obstructive lung disease. $N$ Engl J Med 1991; 324: 1539-1547.

14 Channick RN, Simonneau G, Sitbon O, et al. Effects of the dual endothelin-receptor antagonist bosentan in patients with pulmonary hypertension: a randomised placebocontrolled study. Lancet 2001; 358: 1119-1123.

15 Ulrich S, Speich R, Domenighetti G, et al. Bosentan therapy for chronic thromboembolic pulmonary hypertension. A national open label study assessing the effect of bosentan on haemodynamics, exercise capacity, quality of life, safety and tolerability in patients with chronic thromboembolic pulmonary hypertension (BOCTEPH-Study). Swiss Med Wkly 2007; 137: 573-580.

16 Sitbon O, Gressin V, Speich R, et al. Bosentan for the treatment of human immunodeficiency virus-associated pulmonary arterial hypertension. Am J Respir Crit Care Med 2004; 170: 1212-1217.

17 Galie N, Beghetti M, Gatzoulis MA, et al. Bosentan therapy in patients with Eisenmenger syndrome: a multicenter, double-blind, randomized, placebo-controlled study. Circulation 2006; 114: 48-54.

18 Hoeper MM, Halank M, Marx C, et al. Bosentan therapy for portopulmonary hypertension. Eur Respir J 2005; 25: 502-508.

19 ATS Committee on Proficiency Standards for Clinical Pulmonary Function Laboratories. ATS statement: guidelines for the six-minute walk test. Am J Respir Crit Care Med 2002; 166: 111-117.

20 Lang RM, Bierig M, Devereux RB, et al. Recommendations for chamber quantification: a report from the American Society of Echocardiography's Guidelines and Standards Committee and the Chamber Quantification Writing Group, developed in conjunction with the European Association of Echocardiography, a branch of the European Society of Cardiology. J Am Soc Echocardiogr 2005; 18: 1440-1463.

21 Abbas AE, Fortuin FD, Schiller NB, Appleton CP, Moreno CA, Lester SJ. A simple method for noninvasive estimation of pulmonary vascular resistance. J Am Coll Cardiol 2003; 41: 1021-1027. 
22 Quanjer PH, Tammeling GJ, Cotes JE, Pedersen OF, Peslin R, Yernault JC. Lung volumes and forced ventilatory flows. Report Working Party Standardization of Lung Function Tests, European Community for Steel and Coal. Official Statement of the European Respiratory Society. Eur Respir J 1993; 6: Suppl. 16, s5-s40.

23 Alp S, Skrygan M, Schmidt WE, Bastian A. Sildenafil improves hemodynamic parameters in COPD - an investigation of six patients. Pulm Pharmacol Ther 2006; 19: 386-390.

24 Higenbottam T. Pulmonary hypertension and chronic obstructive pulmonary disease: a case for treatment. Proc Am Thorac Soc 2005; 2: 12-19.

25 Simonneau G, Escourrou P, Duroux P, Lockhart A. Inhibition of hypoxic pulmonary vasoconstriction by nifedipine. N Engl J Med 1981; 304: 1582-1585.

26 Naeije R, Melot C, Mols P, Hallemans R. Effects of vasodilators on hypoxic pulmonary vasoconstriction in normal man. Chest 1982; 82: 404-410.

27 Melot C, Hallemans R, Naeije R, Mols P, Lejeune P. Deleterious effect of nifedipine on pulmonary gas exchange in chronic obstructive pulmonary disease. Am Rev Respir Dis 1984; 130: 612-616.

28 Galie N, Hinderliter AL, Torbicki A, et al. Effects of the oral endothelin-receptor antagonist bosentan on echocardiographic and doppler measures in patients with pulmonary arterial hypertension. J Am Coll Cardiol 2003; 41: 1380-1386.
29 Sajkov D, Cowie RJ, Bradley JA, Mahar L, McEvoy RD. Validation of new pulsed Doppler echocardiographic techniques for assessment of pulmonary hemodynamics. Chest 1993; 103: 1348-1353.

30 Fisher MR, Criner GJ, Fishman AP, et al. Estimating pulmonary artery pressures by echocardiography in patients with emphysema. Eur Respir J 2007; 30: 914-921.

31 Humbert M, Sitbon O, Simonneau G. Treatment of pulmonary arterial hypertension. New Engl J Med 2004; 351: 1425-1436.

32 Vonbank K, Ziesche R, Higenbottam TW, et al. Controlled prospective randomised trial on the effects on pulmonary haemodynamics of the ambulatory long term use of nitric oxide and oxygen in patients with severe COPD. Thorax 2003; 58: 289-293.

33 Chen J, He L, Dinger B, Stensaas L, Fidone S. Role of endothelin and endothelin A-type receptor in adaptation of the carotid body to chronic hypoxia. Am J Physiol 2002; 282: L1314-L1323.

34 Gujic M, Houssiere A, Xhaet O, et al. Does endothelin play a role in chemoreception during acute hypoxia in normal men? Chest 2007; 131: 1467-1472.

35 Rietema H, Holverda S, Boonstra A, Postmus P, VonkNoordegraaf A. Long-term effect of sildenafil on exercise capacity in COPD patients. Eur Respir J 2007; 30: Suppl. 51, 608s. 